Session 3666

\title{
Solution of complex pipe flow problems using spreadsheets in an introductory fluid mechanics course
}

\author{
Mark Schumack \\ Department of Mechanical Engineering \\ University of Detroit Mercy
}

\section{Introduction}

Students of classical fluid mechanics have routinely been taught how to use the Moody chart to solve pipe flow problems. Its use, however, is tedious for even relatively simple flow problems where velocity or diameter is the unknown because an iterative solution is required. Students can avoid repeated references to the Moody chart by using the equation solving functions in their scientific calculators to solve the Colebrook formula for the friction factor, $f$. Even with this tool, however, piping systems with parallel flow paths can still require a large amount of manual iteration to obtain a solution.

Bornt ${ }^{1}$ describes how spreadsheets can be used to calculate pressure drops for steam using an explicit formula for $f$ as a function of Reynolds number and relative roughness. The steam specific volume is a function of pressure, necessitating an iterative solution process that Bornt handles manually. Lester ${ }^{2}$ shows how to use the "Goal Seek" function in Excel ${ }^{\circledR}$ to solve the Colebrook formula for $f$. The Colebrook formula requires an iterative solution for $f$, a task performed automatically by "Goal Seek." While the previous two papers deal with relatively simple single-pipe flows, Streeter and Wylie ${ }^{3}$ describe several computer algorithms and codes for the solution of more complicated pipe network problems. Asking students to write programs for such problems is normally beyond the scope of an introductory fluid mechanics course. Indeed, many practicing engineers, when faced with complex flow problems, will resort to commerciallyavailable software packages. This paper describes an alternative way that uses the nonlinear equation solving capabilities of Excel ${ }^{\circledR}$ to solve complex pipe flow problems in a relatively straightforward fashion. Besides giving students a tool for their future engineering practice, this technique opens up the possibility of providing the undergraduate fluids class with an opportunity to solve a real-world piping system design problem.

The paper describes the method, presents the application to several analysis and design problems, and discusses student response.

II. Using Excel ${ }^{\circledR}$ Solver for Pipe Flow Problems 
The computational solution of pipe flow problems involves the simultaneous solution of the continuity and energy equations along with determination of the friction factor as a function of Reynolds number and relative roughness. The system of equations is nonlinear and thus requires an iterative solution.

Continuity is enforced through the constraint that the net mass flow rate into a junction is equal to zero. The energy equation for steady, uniform, constant property flow through a pipe run (a length of pipe with one inlet and exit, possibly with varying diameter and relative roughness) is as follows:

$$
\frac{p_{1}}{\gamma}+\frac{V_{1}^{2}}{2 g}+z_{1}+\frac{\dot{W}_{p}}{\dot{m} g}=\frac{p_{2}}{\gamma}+\frac{V_{2}^{2}}{2 g}+z_{2}+h_{L}
$$

where $p$ is pressure, $\gamma$ is fluid specific weight, $V$ is fluid velocity, $z$ is fluid elevation, $\dot{W}_{p}$ is pump power input, and head loss, $h_{L}$, is obtained from

$$
h_{L}=\sum f \frac{L}{D} \frac{V^{2}}{2 g}+\sum K_{L} \frac{V^{2}}{2 g} .
$$

The first summation in equation (2) is over lengths of pipe with different roughness values, lengths, or diameters and the second summation is over fittings. The friction factor, $f$, is a function of Reynolds number $\left(\operatorname{Re}=\frac{V D}{v}\right)$ and relative roughness, $\frac{\varepsilon}{D}$. The equivalent roughness, $\varepsilon$, depends on pipe material and age. The friction factor can be evaluated using the Colebrook formula:

$$
\frac{1}{\sqrt{f}}=-2 \log _{10}\left(\frac{\varepsilon / D}{3.7}+\frac{2.51}{\operatorname{Re} \sqrt{f}}\right)
$$

Equation (3) cannot be solved explicitly for $f$, necessitating an iterative solution.

The remainder of this section describes how the Solver tool in Excel $^{\circledR}$ can be used to solve pipe flow problems. Simply put, the energy equation is written for various sections of the piping system and the Colebrook formula is entered for each section of pipe where $f$ is required. Solver is then used to iterate on flow rates (or diameters) and the friction factor until constraints including continuity, the energy equation, and the Colebrook formula are satisfied. A series of progressively more complicated examples will demonstrate the method.

Example 1 A simple example will introduce the Excel ${ }^{\circledR}$ Solver tool and demonstrate how it can be used to calculate $f$ for a given $R e$ and relative roughness. The friction factor is desired for water flowing at $17 \mathrm{~m}^{3} / \mathrm{s}$ through a concrete pipe with a diameter of $2.75 \mathrm{~m}$. Referring to Figure 
1, inputs are entered into the spreadsheet in cells B1 through B4. The relative roughness, velocity, and Reynolds number are calculated in cells F1 through F3. A guessed value for $f$ is placed in cell F5. The left hand side of equation (3) is entered into cell E8 and the right hand side of the same equation is entered into cell F8. Solver is chosen from the Tools menu, and entries are made as shown in Figure 2. When the "Solve" button is pushed, Solver changes the value in cell F5 (f) until the constraints are satisfied (i.e., until the left-hand and right-hand sides of the Colebrook formula, equation (3), are equal). Note that since only one cell is being changed, only one constraint is necessary, but a second constraint is added to ensure convergence. This second constraint (that the value in cell $\mathrm{F} 5$ remain greater than 0.001 ) keeps $f$ from going negative during the iterative process and thus avoids the calculation being aborted due to undefined values. Also, the "Set Target Cell" box is left empty.

\begin{tabular}{|c|c|c|c|c|c|c|c|}
\hline & A & $\mathrm{B}$ & $\mathrm{C}$ & D & $E$ & $\mathrm{~F}$ & \\
\hline 1 & $D=$ & 2.75 & $m$ & & $e / D=$ & 0.000109091 & \\
\hline 2 & $e=$ & 0.0003 & $\mathrm{~m}$ & & $V=$ & 2.862158315 & $\mathrm{~m} / \mathrm{s}$ \\
\hline 3 & $Q=$ & 17 & $\mathrm{~m}^{3} / \mathrm{s}$ & & $\mathrm{Re}=$ & $7.03 E+06$ & \\
\hline 4 & $n u=$ & 1.12E-06 & $\mathrm{m}^{2} / \mathrm{s}$ & & & & \\
\hline 5 & & & & & $f=$ & 0.012425024 & \\
\hline 6 & & & & & & & \\
\hline 7 & & & & & Colebrook LHS & Colebrook RHS & \\
\hline 8 & & & & & 8.971217591 & $8.97 E+00$ & \\
\hline
\end{tabular}

Figure 1. Spreadsheet setup for Example 1.

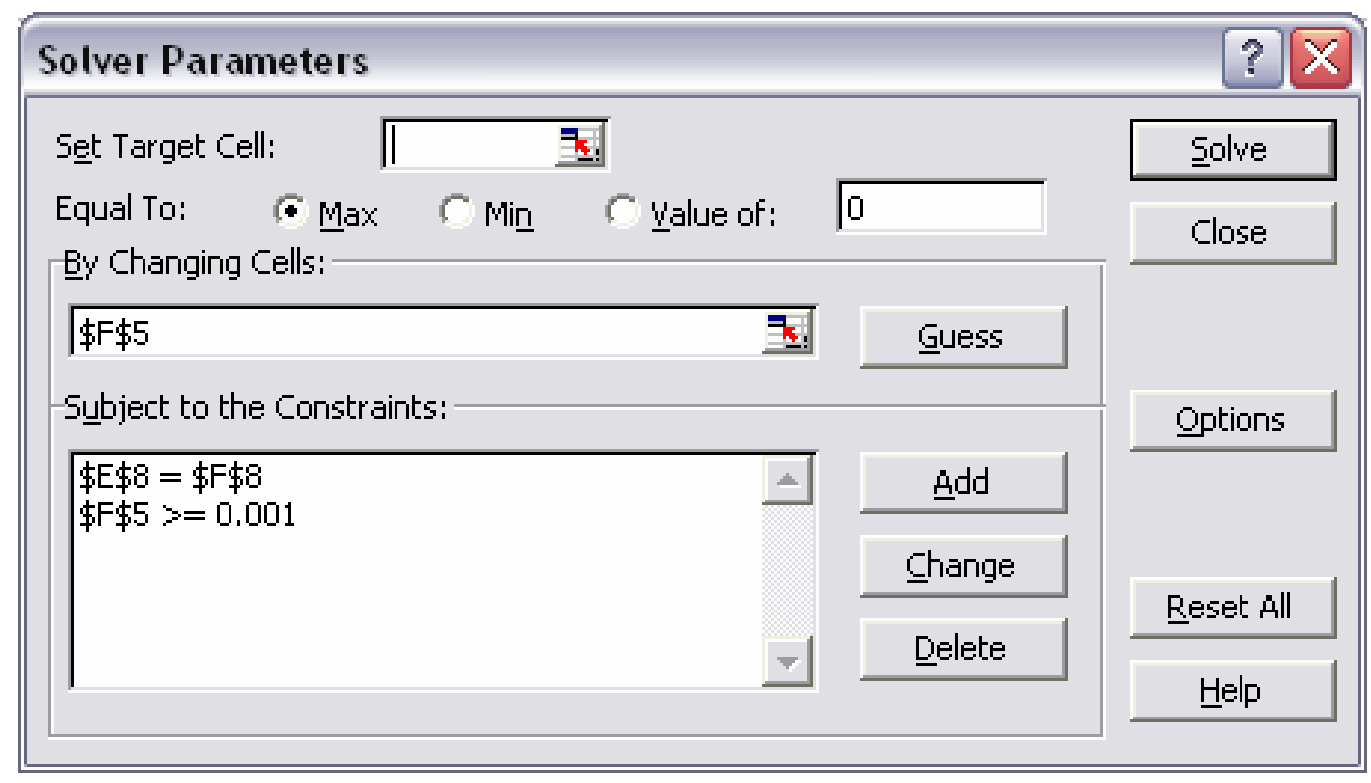

Figure 2. The Solver menu for Example 1. For most of the applications described in this paper, the first two lines of the menu ("Set Target Cell" and "Equal To") are irrelevant and the "Set Target Cell" box should be empty. 
Example 2 The next example shows how Solver can be used to calculate volumetric flowrate for a given pressure drop and pipe diameter. The flowrate for water traveling through a horizontal $300 \mathrm{~m}$-long cast iron pipe with a diameter of $0.6 \mathrm{~m}$ and a pressure drop of $17.2 \mathrm{kPa}$ is to be found. The energy equation (1) and equation (2) can be combined to give:

$$
\frac{\Delta p}{\gamma}=f \frac{L}{D} \frac{V^{2}}{2 g}
$$

where $\Delta p$ is the upstream minus the downstream pressure, $p_{1}-p_{2}$. The volumetric flowrate is related to the velocity via $Q=V A$ where $A$ is the pipe cross-sectional area. Equation (4) is a transcendental equation for velocity, with $f$ being related to $V$ through the relationship between $f$ and $R e$ in the Colebrook formula. A manual iterative approach would consist of guessing $f$, calculating $V$ from equation (4), calculating $R e$, determining a new value of $f$ from the Moody chart or Colebrook formula, and so on until convergence. To use Solver, the problem can be viewed as a system of two simultaneous equations (3) and (4) for two unknowns $f$ and $V$. Referring to Figure 3, inputs are entered into cells B1 through B6, initial guesses for velocity and friction factor into cells B8 and B9, and equations for calculated values into cells F1 through F3. The left- and right-hand sides of equation (3) are entered into cells E7 and F7 as in example 1, and the left- and right-hand sides of equation (4) are entered into E10 and F10.

\begin{tabular}{|c|c|c|c|c|c|c|c|}
\hline & $\mathrm{A}$ & B & $\mathrm{C}$ & D & $E$ & $\mathrm{~F}$ & $G$ \\
\hline 1 & $\mathrm{D}=$ & 0.6 & $\mathrm{~m}$ & & $e / D=$ & 0.000433333 & \\
\hline 2 & $e=$ & 2.60E-04 & $m$ & & $\mathrm{Re}=$ & 1.09E+06 & \\
\hline 3 & $\Delta p=$ & 17.2 & $\mathrm{kPa}$ & & $Q=$ & 0.573980769 & $\mathrm{~m}^{3} / \mathrm{s}$ \\
\hline 4 & nu= & 1.12E-06 & $\mathrm{m}^{2} / \mathrm{s}$ & & & & \\
\hline 5 & gamma= & 9.8 & $\mathrm{kN} / \mathrm{m}^{3}$ & & & & \\
\hline 6 & $L=$ & $3.00 \mathrm{E}+02$ & $\mathrm{~m}$ & & Colebrook LHS & Colebrook RHS & \\
\hline 7 & & & & & 7.739462492 & $7.74 \mathrm{E}+00$ & \\
\hline 8 & $V=$ & 2.030042 & $\mathrm{~m} / \mathrm{s}$ & & & & \\
\hline 9 & $f=$ & 0.016695 & & & energy LHS & energy RHS & \\
\hline 10 & & & & & 1.755102041 & 1.755101564 & \\
\hline
\end{tabular}

Figure 3. Spreadsheet setup for Example 2.

The Solver parameters are set as shown in Figure 4. The two unknowns are represented by the two cells in the "By Changing Cells" box and the two equations are represented by the two constraints E7 $=$ F7 and E10 $=$ F10 in the "Subject to the Constraints" box. The additional two constraints (B8 and B9 greater than 0.001) ensure that the solution remains physical. Pushing the "Solve" button causes Solver to change the values of $V$ and $f$ in cells B8 and B9 until the Colebrook and energy equations are satisfied, resulting in the volumetric flowrate seen in Figure 3 in cell F3. 


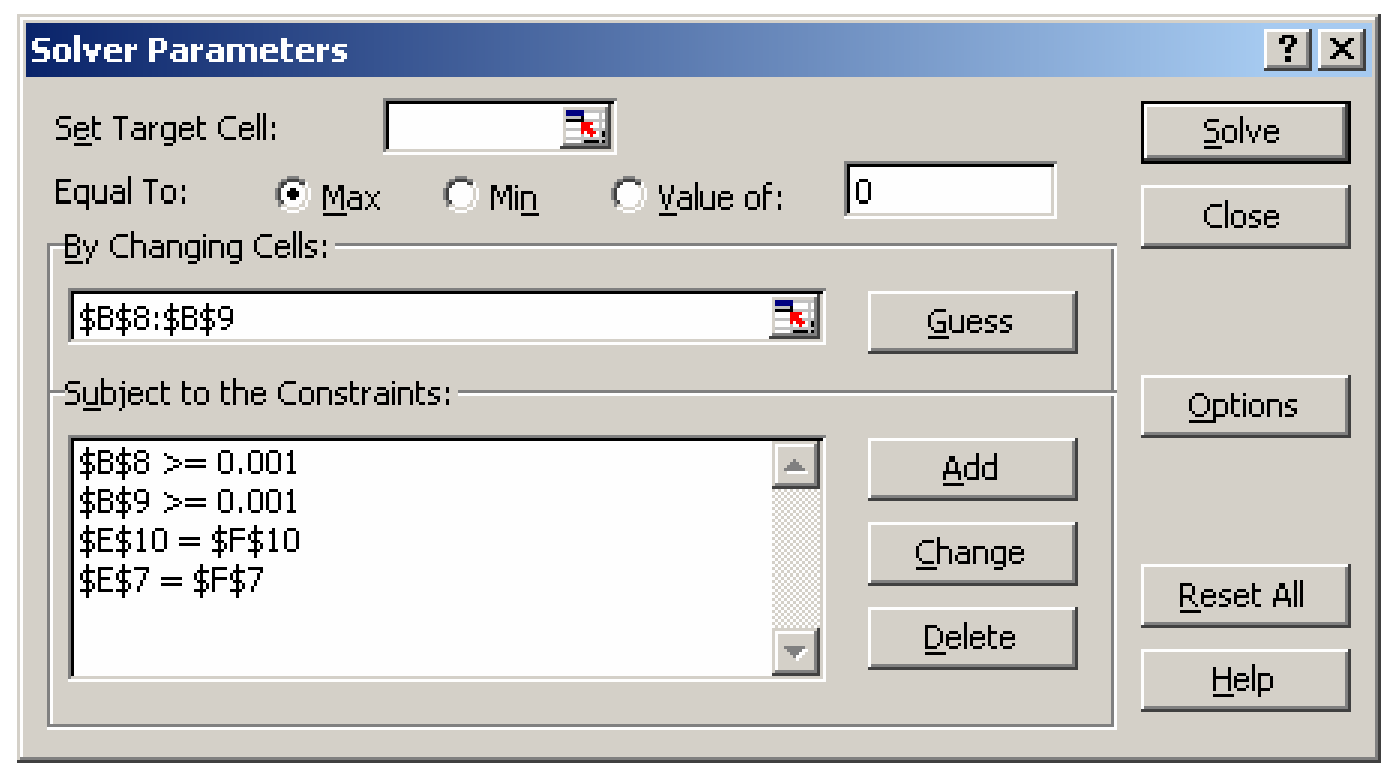

Figure 4. Solver parameters for Example 2.

Example 3 Another problem requiring iteration is determination of pipe diameter for a given flowrate and pressure drop. As an example, the smallest allowable diameter of the pump suction pipe for the arrangement shown in Figure 5 is to be found with the restriction that the pressure at the pump inlet must be greater than $0.1217 \mathrm{psia}$ (this problem is similar to a textbook problem from Fox and McDonald ${ }^{4}$ ). The material is commercial steel and the fluid is water.

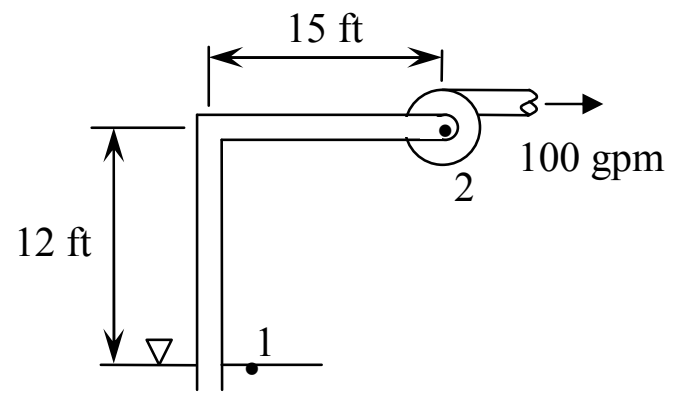

Figure 5. Schematic for pipe diameter problem.

The energy equation between points 1 and 2 reduces to (for suction from a large reservoir)

$$
\frac{p_{1}}{\gamma}+z_{1}=\frac{p_{2}}{\gamma}+\frac{V_{2}^{2}}{2 g}+z_{2}+h_{L}
$$

where, neglecting minor losses, 


$$
h_{L}=f \frac{L}{D} \frac{V^{2}}{2 g}
$$

Noting that $V=V_{2}$ and with $z_{1}=0$, these two equations are combined to give

$$
\frac{p_{1}}{\gamma}=\frac{p_{2}}{\gamma}+\frac{V_{2}^{2}}{2 g}+z_{2}+f \frac{L}{D} \frac{V_{2}^{2}}{2 g} .
$$

With $V_{2}$ related to $D$ through $Q=V_{2} \frac{\pi D^{2}}{4}$ equation (5) has $f$ and $D$ as unknowns. The

Colebrook formula (equation (3)) completes the formulation. The spreadsheet setup and input of Solver parameters proceeds similar to the previous example as shown in Figures 6 and 7. Initial guesses for $f$ and $D$ are entered into cells B11 and B12; the Colebrook formula is satisfied through the constraint that cell G9 = cell H9 and the energy equation is satisfied through the constraint that cell G12 = cell H12. The limiting diameter is calculated as 1.53 inches; the final pipe size should be specified as a commercially available $1 \frac{1}{2}$ inch schedule 40 or even 2 -inch diameter pipe in order to avoid violating the pressure limitation as the pipe ages and the relative

\begin{tabular}{|c|c|c|c|c|c|c|c|c|c|}
\hline & A & $B$ & C & D & $E$ & $\mathrm{~F}$ & $G$ & $\mathrm{H}$ & \\
\hline 1 & $e=$ & 0.00015 & $\mathrm{ft}$ & & & & $e / D=$ & 9.82992E-05 & \\
\hline 2 & $\mathrm{Q}=$ & 100 & $\mathrm{gpm}=$ & 0.222816 & $\mathrm{ft}^{3} / \mathrm{s}$ & & $V_{2}=$ & 17.54434812 & $2 \mathrm{ft} / \mathrm{s}$ \\
\hline 3 & $L=$ & 27 & $\mathrm{ft}$ & & & & $\mathrm{Re}=$ & $1.84 \mathrm{E}+05$ & \\
\hline 4 & $\mathrm{p} 1=$ & 14.7 & $p \operatorname{sia}=$ & 2116.8 & $\mathrm{lb} / \mathrm{t}^{2}$ & & & & \\
\hline 5 & $\mathrm{p} 2=$ & 0.1217 & psia $=$ & 17.5248 & $\mathrm{lb} / \mathrm{ft}^{2}$ & & & & \\
\hline 6 & $\mathrm{z} 2=$ & 12 & $\mathrm{ft}$ & & & & & & \\
\hline 7 & nu= & $1.21 \mathrm{E}-05$ & $\mathrm{ft}^{2} / \mathrm{s}$ & & & & & & \\
\hline 8 & gamma= & 62.4 & $\mathrm{lb} / \mathrm{tt}^{3}$ & & & & Colebrook LHS & Colebrook RHS & \\
\hline 9 & & & & & & & 7.757702058 & $7.76 \mathrm{E}+00$ & \\
\hline 10 & & & & & & & & & \\
\hline 11 & $f=$ & 0.016616 & & & & & energy LHS & energy RHS & \\
\hline 12 & $D=$ & 1.525953 & in $=$ & 0.127163 & $\mathrm{ft}$ & & 33.92307692 & 33.92307669 & \\
\hline
\end{tabular}
roughness increases.

Figure 6. Spreadsheet setup for Example 3. 


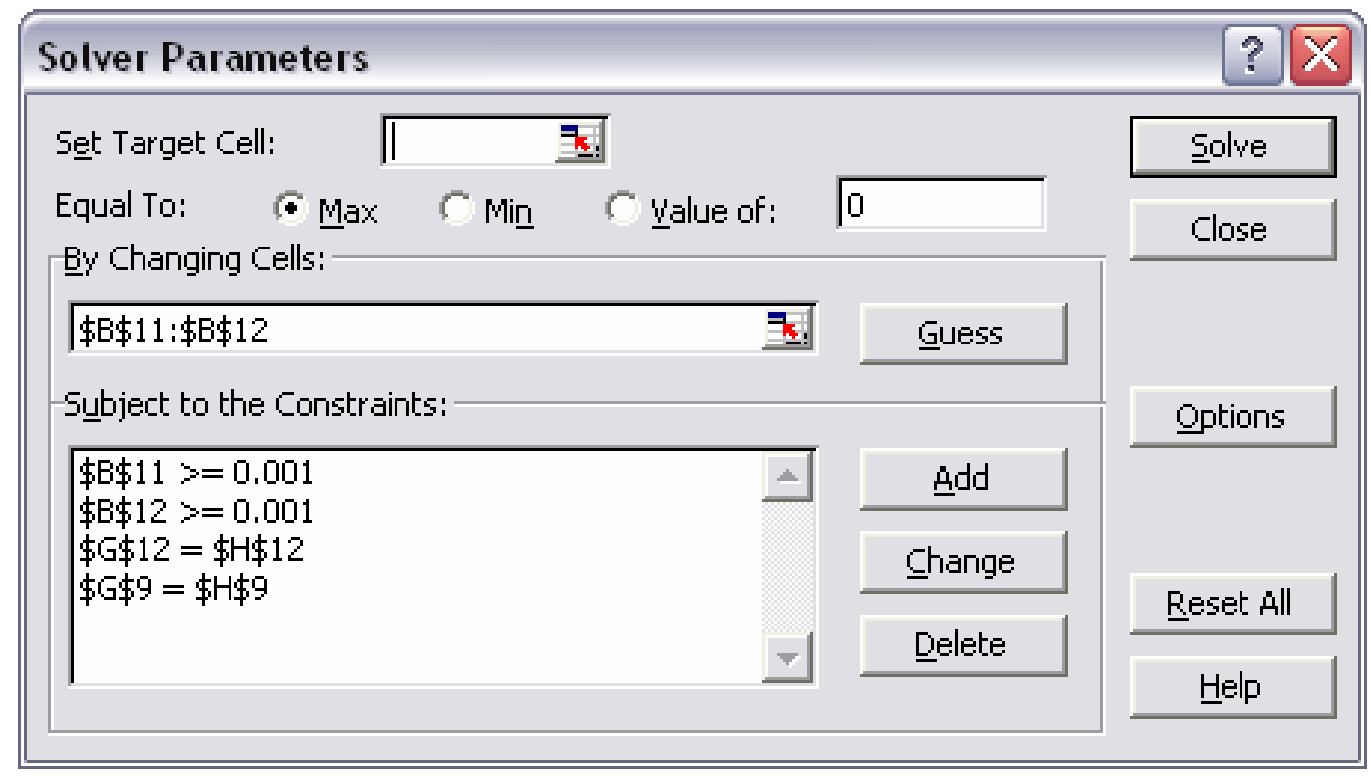

Figure 7. Solver parameters for Example 3.

Example 4 A final example demonstrates the use of Solver to analyze piping systems with parallel flow paths. This problem was given as a design project in Fall 2003 to undergraduate students in an introductory fluid mechanics course. Referring to Figure 8 , the problem statement is:

An air conditioning system is designed to provide cold water to a series of chillers as shown in the figure. Cold water at $38^{\circ} \mathrm{F}$ travels through $60 \mathrm{ft}$ of $\frac{1}{2}$ inch pipe through $20180^{\circ}$ bends within each chiller. Some details of the pipe runs are given below; you specify other characteristics such as pipe diameter or valve openings with the goal of providing an equal flowrate through each chiller at the lowest cost. Cost considerations include cost of the pump, cost of the pipe, and annual operating costs for the pump. You may assume an electricity cost of $\$ 0.10 / \mathrm{kW} \mathrm{h}$. Pump and pipe costs can be obtained from supplier catalogs on the web (one good place to go is Grainger, an industrial supply company). The pump type should be centrifugal. Make sure you characterize your design clearly but concisely, including all pipe sizes, the flow rate through each run, pump power, and material and operating costs. (Note: you do not have to specify costs for the heat exchanger, chillers, valves, or elbows). 


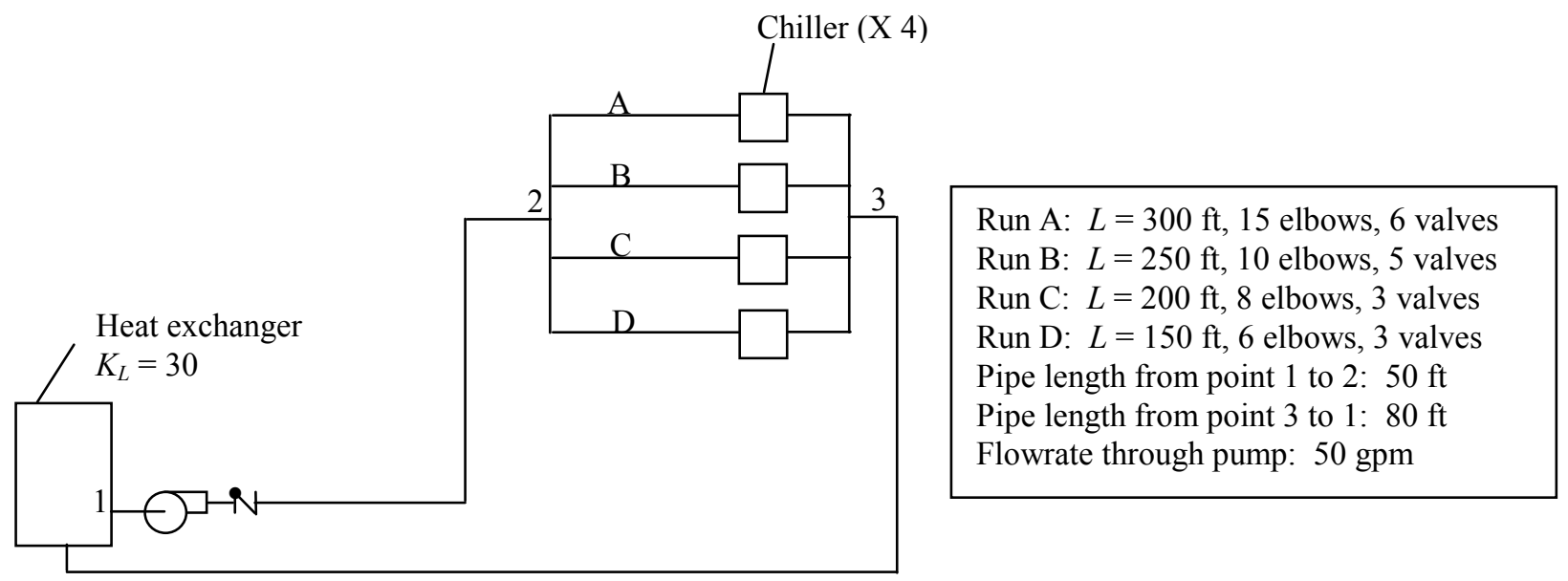

Figure 8. Schematic for design project.

Recognition that the pressure drop from 2 to 3 is the same for each of the four runs A through D leads to

$$
\frac{p_{2}-p_{3}}{\gamma}=h_{L_{A}}=h_{L_{B}}=h_{L_{C}}=h_{L_{D}}
$$

where the head loss through each run is obtained from an equation of the form

$$
h_{L}=f \frac{L}{D} \frac{V^{2}}{2 g}+\sum K_{L} \frac{V^{2}}{2 g}+h_{L_{\text {chiller }}},
$$

with the head loss through each chiller determined by

$$
h_{L_{\text {chiller }}}=f \frac{L}{D} \frac{V^{2}}{2 g}+20 K_{\text {bend }} \frac{V^{2}}{2 g} \text {. }
$$

Writing the energy equation from points 1 to 2 and from 3 to 1 and combining these equations with equation (6) results in the following expression for pump power:

$$
\frac{\dot{W}_{p}}{\dot{m} g}=h_{L_{12}}+h_{L_{23}}+h_{L_{31}}
$$

where $h_{L_{23}}=\frac{p_{2}-p_{3}}{\gamma}$.

The head losses from point 1 to 2 and from 3 to 1 can be obtained from equations of the form 


$$
h_{L}=f \frac{L}{D} \frac{V^{2}}{2 g}+\sum K_{L} \frac{V^{2}}{2 g} \text {. }
$$

The design approach involves choosing pipe material and diameters for the pipe runs from 1 to 2 and 3 to 1. (Once pump power is determined, manufacturer's data for typical suction and discharge openings for pumps with the appropriate power and flowrate characteristics can be used to refine these diameters.) With the given flowrate, chosen pipe material and diameters, and other specifications from Figure $8, h_{L_{12}}$ and $h_{L_{31}}$ can be calculated. Since each of the four parallel flow paths ideally should carry the same flowrate $(50 / 4=12.5 \mathrm{gpm})$, the problem becomes one of determining pipe diameters for runs A through $\mathrm{D}$. One of the diameters must be specified; once this is done $p_{2}-p_{3}$ can be calculated from one of the equalities expressed by (6) and the pump power can be determined from equation (7). The three remaining diameters are calculated in an iterative fashion using Solver from the three remaining equalities in (6), in a fashion similar to that described in Example 3. Solver must also be used as described in Example 1 to determine the friction factors for each of the six runs.

Although lengthier than the previous three examples, the setup for this problem is straightforward and will not be described in detail here. Only some key results and student performance will be discussed. The results assume that the pipe material has a relative roughness equivalent to that of drawn tubing and that the pump efficiency is $100 \%$.

Specifying a diameter of 1.5 inches for the pipe from point 1 to 2 (pump discharge), 2 inches for the pipe from 3 to 1 (pump suction), and 1 inch for the pipe in run A leads to the diameters shown in Table 1 for runs A through D in order to maintain an equal flowrate through all runs.

\begin{tabular}{|l|l|l|l|l|}
\hline Run & A & B & C & D \\
\hline Internal Diameter (inches) & 1 & 0.96 & 0.92 & 0.86 \\
\hline
\end{tabular}

Table 1. Calculated pipe diameters for Example 4.

Since the diameters are close to one another, a single nominal pipe size, say 1 inch, could be specified for all runs. This would mean the flowrates would be unequal, but probably not significantly different from one another. The corresponding pump power is calculated to be 3.7 $\mathrm{hp}$ and the pressure rise across the pump is calculated as $127 \mathrm{psi}$. With this power rating, pressure rise, and given flowrate, a pump can be chosen. Once the pump is chosen, its headcapacity operating characteristics could be matched with the system characteristics to refine the operating parameters, but the students were not asked to go this far.

The 1-inch pipe diameter for run $\mathrm{A}$ is by no means the best choice. As the pipe diameters for the runs increase, the cost for piping increases, while the pump power and cost decrease due to the lower head losses. This suggests an optimization problem. An examination of manufacturer's copper tubing cost data leads to a rough figure of $\$ 1.75$ per inch diameter per foot length. 
Similarly, a survey of manufacturer's data suggests that pump cost in dollars can be approximated by the relation $220 \dot{W}_{p}+150$, where $\dot{W}_{p}$ is in horsepower. Figure 9 shows how pump, pipe, and total cost vary with the pipe diameter in run A. By adding a constraint that the total cost be a minimum, Solver can be used to calculate the optimum pipe diameter in run A. The additional constraint is entered into the "Set Target Cell" box in the Solver menu, with the cell reference corresponding to the cell where the total cost is calculated. The "Min" bullet in the "Equal To" line in the Solver menu is checked. The pipe diameter resulting in lowest total cost is 0.83 inches.

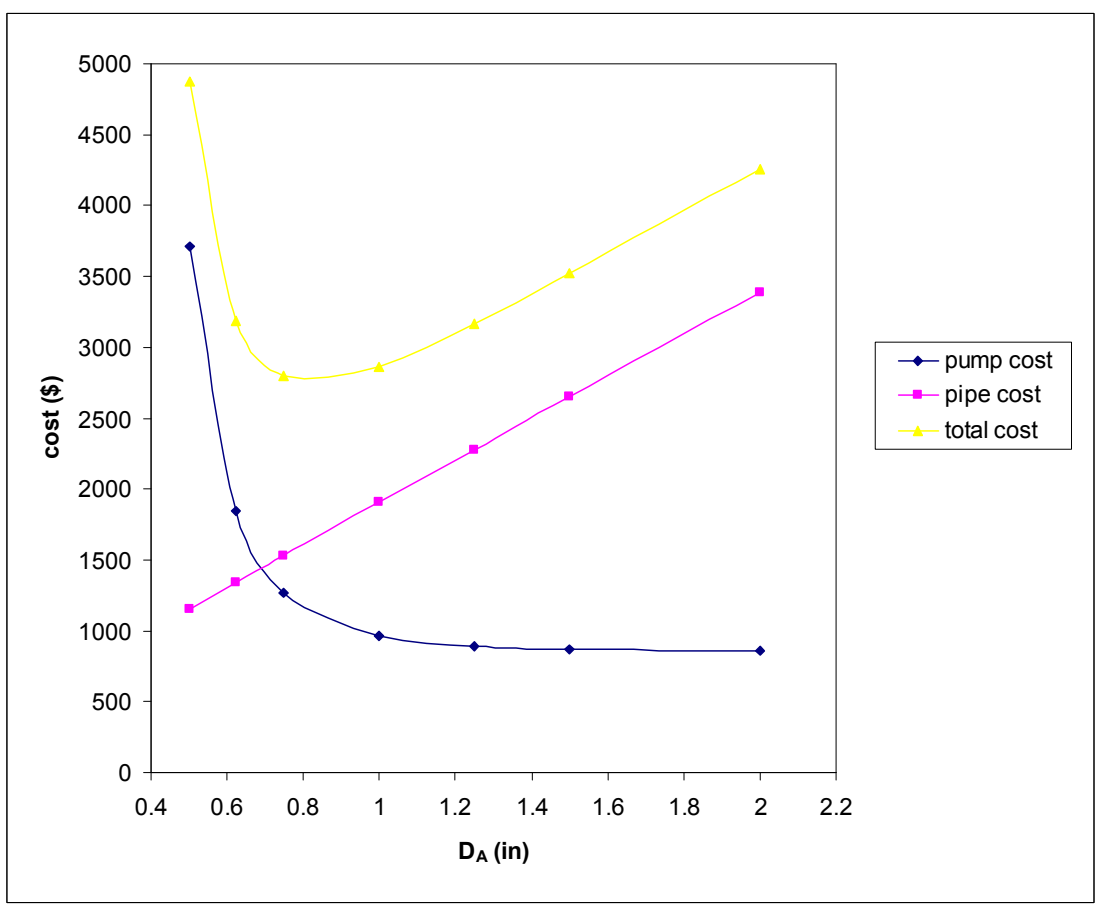

Figure 9. Relationship between cost and pipe diameter for run A from Example 4.

After some instructor guidance for determining the pump suction and discharge piping sizes, and pipe size for run A, students were generally able to use Solver to calculate pipe diameters for runs $\mathrm{B}$ through $\mathrm{D}$. They were able to price the piping and pump without any apparent problems. None of the students recalculated flowrates through the runs after adjusting calculated pipe diameters to reflect nominal pipe sizes; some students did mention that control valves could be used to balance the flow rates through the four runs if necessary. Also, no students thought of setting up and solving an optimization problem as described above. This failure of the students to perform additional calculations after specifying an initial design was likely due to an end-ofterm time crunch: some students had multiple design projects due from other classes beside this one. A representative set of design specifications from student submissions is shown in Table 2. 


\begin{tabular}{|l|l|}
\hline Item & Specification \\
\hline Run A pipe diameter & $1 \mathrm{in}$ \\
\hline Run B pipe diameter & $0.96 \mathrm{in}$ \\
\hline Run C pipe diameter & $0.92 \mathrm{in}$ \\
\hline Run D pipe diameter & $0.86 \mathrm{in}$ \\
\hline Suction pipe diameter & $1.25 \mathrm{in}$ \\
\hline Discharge pipe diameter & $1.25 \mathrm{in}$ \\
\hline Pump power & $5 \mathrm{hp}$ \\
\hline Pipe cost & $\$ 1185$ \\
\hline Pump cost & $\$ 1455$ \\
\hline Operating cost & $\$ 0.37$ hour \\
\hline
\end{tabular}

Table 2. Representative student design specifications for Example 4.

\section{Assessment}

The author has been teaching students how to use Solver to solve pipe flow problems for several years in undergraduate fluid mechanics. The use of Solver is normally introduced only after the students have learned to use the Moody chart and performed some iterative calculations by hand. Student performance and anecdotal evidence suggest that students learned the Solver tool well and appreciated its benefits above manual methods.

In Fall 2003, students in an undergraduate fluid mechanics class were given a special survey regarding their impressions of Solver. In addition, two of the course outcomes, that students are able to "use the computer to solve fluid dynamics problems" and "solve an open ended design problem" were also relevant to student perceptions about Solver and were rated in a student outcome survey. The class size was 9 , and 8 students completed the surveys (the small class size was due to the fact that the Term I offering is intended mainly for non-mechanical engineering students). Average results for each of the survey questions are shown in Figure 10. The numerical rating scale ranged from 5 (strongly agree) to 1 (strongly disagree). Most of the survey items garnered average scores between 4 and 5 , suggesting that students recognized the value in using Solver to solve pipe flow problems. One of the items, "I found Solver easy to use" scored a 3.875, indicating that some students struggled with learning the tool. The two items from the course outcome survey (items 8 and 9 in Figure 10) garnered relatively low scores. The score for item 9 , in particular, probably reflects student frustration when faced with an open-ended design problem after a term filled with typical well-posed end-of-chapter problems having unique solutions. 


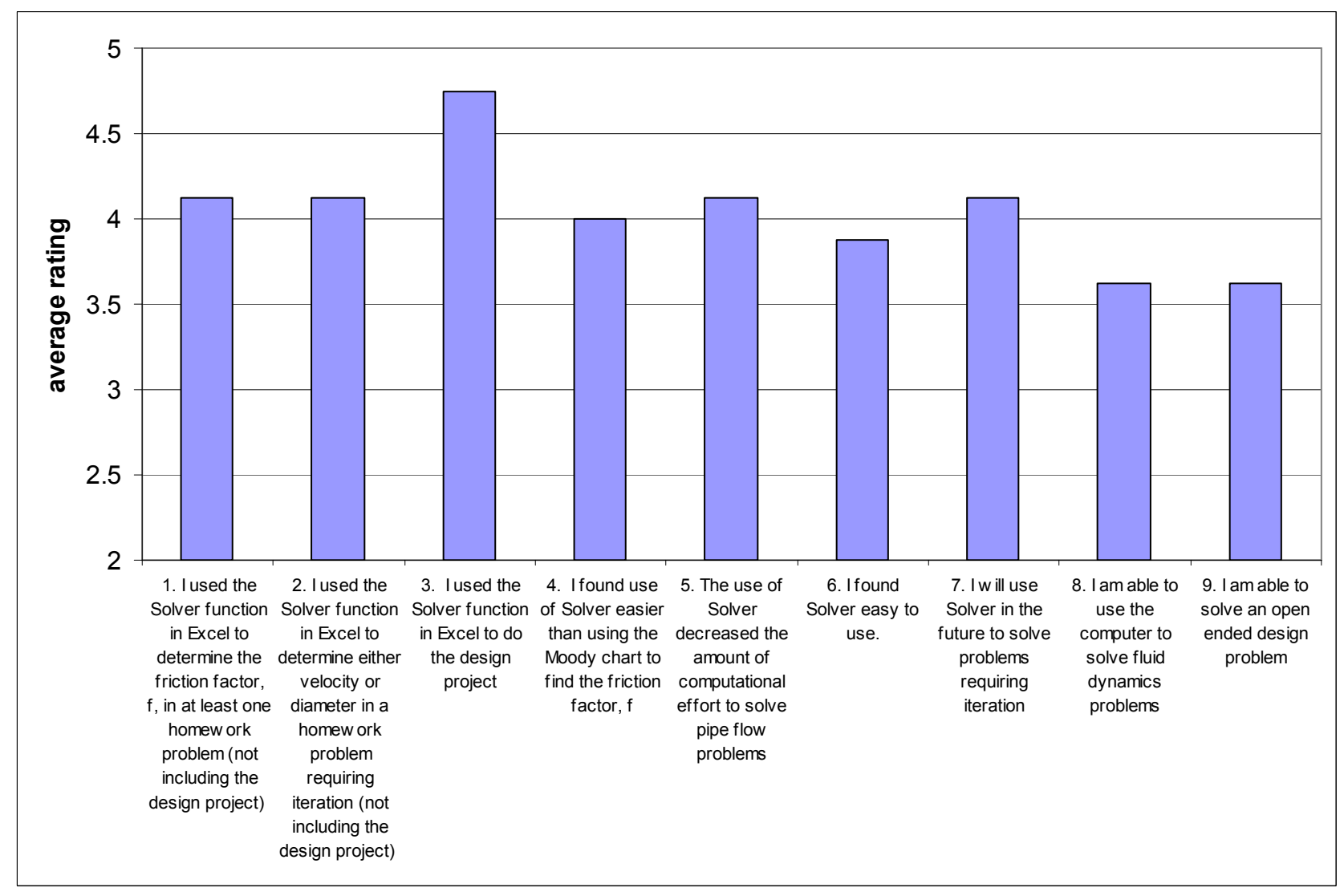

Figure 10. Average student ratings for the survey questions. The ratings range from $5=$ strongly agree to $1=$ strongly disagree.

\section{Conclusions}

Computers can automate the traditionally tedious iterative solutions to certain types of pipe flow problems. The ubiquitous spreadsheet package makes Excel ${ }^{\circledR}$ Solver an especially convenient tool for performing the calculations. This paper has described how to use Solver to find the friction factor and calculate flowrates and diameters for single- and multiple-path piping systems. Students have learned to use the tool relatively well and have demonstrated an appreciation for its advantages over more time-consuming and cumbersome manual methods.

\section{Bibliography}

1. Bornt, Butch. Spreadsheets cut calculation time for piping system design. Power Engineering, vol. 97, no. 3, pp. 38-39 (March 1993).

2. Lester, Thomas G. Calculating Pressure Drops in Piping Systems. ASHRAE Journal, vol. 44, no. 9, pp. 41-43 (September 2002).

3. Streeter, Victor L. and Wylie, E. Benjamin. Fluid Mechanics, $8^{\text {th }}$ Edition, McGraw-Hill (1985).

4. Fox, Robert W. and McDonald, Alan T. Introduction to Fluid Mechanics, $3^{\text {rd }}$ Edition, John Wiley \& Sons (1985). 
MARK SCHUMACK

Mark Schumack is Associate Professor of Mechanical Engineering at the University of Detroit Mercy. He teaches courses in heat transfer, thermodynamics, fluid mechanics, and energy systems. His research interests include thermal/fluid modeling using computational techniques, with applications in the automotive and manufacturing fields. Dr. Schumack earned his BS, MS, and Ph.D. degrees in Mechanical Engineering from the University of Michigan. 